\title{
Self-processing photopolymer materials for versatile design and fabrication of holographic sensors and interactive holograms
}

Dervil Cody

Technological University Dublin, dervil.cody@tudublin.ie

Sabad-e Gul

Technological University Dublin, sabade.gul@tudublin.ie

Tatsiana Mikulchyk

Technological University Dublin, Tatsiana.mikulchyk@tudublin.ie

See next page for additional authors

Follow this and additional works at: https://arrow.tudublin.ie/cieoart

Part of the Optics Commons

\section{Recommended Citation}

Dervil Cody, Sabad-e Gul, Tatsiana Mikulchyk, Muhammad Irfan, Anastasia Kharchenko, Kamila Goldyn, Suzanne Martin, Svetlana Mintova, John Cassidy, and Izabela Naydenova, "Self-processing photopolymer materials for versatile design and fabrication of holographic sensors and interactive holograms," Appl. Opt. 57, E173-E183 (2018)

This Article is brought to you for free and open access by the Centre for Industrial and Engineering Optics at ARROW@TU Dublin. It has been accepted for inclusion in Articles by an authorized administrator of ARROW@TU

Dublin. For more information, please contact

arrow.admin@tudublin.ie, aisling.coyne@tudublin.ie, gerard.connolly@tudublin.ie.

Funder: Technological University Dublin

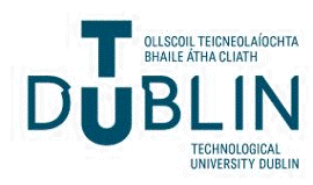




\section{Authors}

Dervil Cody, Sabad-e Gul, Tatsiana Mikulchyk, Muhammad Irfan, Anastasia Kharchenko, Kamila Goldyn, Suzanne Martin, Svetlana Mintova, John Cassidy, and Izabela Naydenova 


\title{
applied optics
}

\section{Self-processing photopolymer materials for versatile design and fabrication of holographic sensors and interactive holograms}

\author{
Dervil Cody, ${ }^{1}$ (i) Sabad-e Gul, ${ }^{1}$ (i) Tatsiana Mikulchyk, ${ }^{1}$ (i) Muhammad Irfan, ${ }^{1}$ (i) Anastasia \\ Kharchenko, ${ }^{2}$ Kamila Goldyn, ${ }^{2}$ Suzanne Martin, ${ }^{1}$ (i) Svetlana Mintova, ${ }^{2}$ John Cassidy, ${ }^{3}$ and \\ IzABELA NAYDENOVA ${ }^{1, *}$ (1) \\ ${ }^{1}$ Centre for Industrial and Engineering Optics, School of Physics and Clinical \& Optometric Sciences, College of Science and Health, \\ Dublin Institute of Technology, Kevin Street, Dublin D08NF82, Ireland \\ ${ }^{2}$ Laboratoire Catalyse \& Spectrochimie, ENSICAEN, Université de Caen Basse-Normandie, CNRS, 6, Boulevard du Maréchal Juin, \\ 14050 Caen Cedex, France \\ ${ }^{3}$ School of Chemical and Pharmaceutical Sciences, College of Sciences and Health, Dublin Institute of Technology, Kevin Street, \\ Dublin D08NF82, Ireland \\ *Corresponding author: izabela.naydenova@dit.ie
}

Received 3 April 2018; revised 28 May 2018; accepted 29 June 2018; posted 29 June 2018 (Doc. ID 327457); published 24 July 2018

\begin{abstract}
The aim of this paper is to discuss the benefits as well as the limitations of utilizing photopolymer materials in the design of holograms that are responsive to changes in their environment, such as changes in the concentration of a specific substance, temperature, and pressure. Three different case studies are presented, including both surface and volume phase holograms, in order to demonstrate the flexibility in the approach of utilizing holographic photopolymers for the design of sensors and interactive optical devices. First, a functionalized surface relief hologram is demonstrated to operate as an optical sensor for the detection of metal ions in water. The sensitivity and selectivity of the sensor are investigated. The second example demonstrates a volume transmission hologram recorded in a temperature-sensitive photopolymer and the memory effects of its exposure to elevated temperature. Finally, a pressure-sensitive reflection hologram that changes color under application of pressure is characterized, and its potential application in document authentication is described. (๑) 2018 Optical Society of America
\end{abstract}

OCIS codes: (090.0090) Holography; (050.1950) Diffraction gratings; (130.6010) Sensors; (160.5335) Photosensitive materials; (160.5470) Polymers.

\section{INTRODUCTION}

Interactive holograms have been a subject of extensive investigations for many years due to their many potential applications, among which are electro-optical switchable devices. such as beam splitters and phase modulators $[1,2]$, holographic sensors [3] for detection of biological [4-6] and chemical substances [7-14], and holographic indicators that change their properties to indicate a change in their environment in terms of pressure, humidity, temperature, etc. [15-17]. Three main approaches have been utilized in order to achieve interactive capability of the holograms: (1) the holographic recording material has been functionalized before recording by incorporation of nanoparticles [10-12,17-19] or suitable monomers [3,17,20-22], (2) the layer containing the hologram has been structured in an appropriate manner, for example, using molecularly imprinted layers [23-25], or (3) the holograms have been modified after recording, for example, by coating with a functionalizing layer [26-29]. Each of these approaches has its advantages and challenges, as discussed in the next sections.

\section{A. Functionalization by Compositional Variation of the Holographic Recording Material}

This is typically achieved by selection of monomer molecules that can provide additional functionality $[3,17,22]$ with incorporation of liquid crystal molecules [1,2], and inorganic or organic nanoparticles [3,10-12,17-19]. The main challenge of this approach is the optimization of the photopolymer layer optical quality and the ability to record high efficiency holograms after the incorporation of the functionalizing compoment. The addition of nanoparticles is typically a particularly challenging approach, since it introduces additional scattering due to the difference in the refractive index of the host material and the nanoparticles [30]. Another challenge is the need for a careful consideration of the sensor's dynamic range and the range of operation. This is particularly important when the 
interrogated parameter is the diffraction efficiency (DE) of the hologram. The DE dependence on the changing characteristics of the hologram under external stimuli, such as refractive index modulation, thickness, and effective refractive index, is close to linear only for well-specified regions.

\section{B. Functionalization During Holographic Recording}

This approach is used, for example, in holographic molecularly imprinted polymer (MIP) films, which are structured by using interference photolithography. MIPs are prepared by templating at the molecular level by photopolymerization. The polymerization is performed in the presence of a template molecule (target), and the cross-linked polymer matrix consists of cavities that are complementary to the template molecule in terms of shape, size, and position of functional groups. Hence, MIPs have the capability to bind to target molecules with high affinity and specificity. An example of such a sensor for detection of testosterone is reported in Refs. [24,25].

\section{Post-Recording Functionalization of the Hologram}

This is achieved by impregnation of the hologram [3] or coating of the hologram's surface with a chemical substance providing the sensitivity to a specific analyte [26-29]. The challenge in this approach is the fine-tuning of the properties of the initial hologram in order to achieve optimum dynamic range and sensitivity of the sensor. Surface holograms are generaly thin, and the maximum achievable DE in this case is approximately $33 \%$.

In all three approaches to fabrication of the holographic sensors and interactive optical devices, the careful selection of the initial properties of the hologram plays a crucial role $[31,32]$. For that reason, using a self-processing photopolymer, which allows monitoring in real time, the DE of the holographic structure is the suggested method in the current paper. The successful sensor design is demonstrated in three separate case studies. Both surface and volume gratings have been utilized, and the benefits and limitations of both transmission and reflection holograms are discussed. Through these case studies, this paper presents a novel platform of responsive photopolymers, as well as specific novel developments in each case. In Section 4.A, experimental data demonstrating the sensitivity of a zeolite coated surface relief structure to lead $\left(\mathrm{Pb}^{+2}\right)$ and a comparison of the response to other metal ions are reported for the first time. A new study demonstrating the importance of the time spent at elevated temperature on the reversibility of the change in $\mathrm{DE}$ of volume transmission gratings in composition
C is reported in Section 4.B. A characterization of a pressure sensor based on the reflection hologram recorded in composition $\mathrm{D}$ is presented in Section 4.C for the first time, to the best of our knowledge.

\section{PRINCIPLE OF OPERATION OF THE SENSORS}

A schematic presentation of the principle of operation of the holographic sensors demonstrated in the article is given in Fig. 1. A surface relief structure coated with a Linde type L (LTL) zeolite nanoparticle containing layer is functionalized to selectively capture metal ions [Fig. 1(a)]. Exposure to the target analyte leads to a change in the DE of the structure due to variation of the refractive index modulation in the grating as a result of the spatially varying adsorption of the analyte in the zeolite rich regions. Volume transmission phase gratingbased sensors are typically interrogated by measuring their $\mathrm{DE}$, which changes as a result of the changed thickness of the grating, refractive index modulation, and grating period [Fig. 1(b)]. Both types of sensors [Figs. 1(a) and 1(b)] require an electronic read out of the signal. Volume reflection phase gratings [Fig. 1(c)] are most often used for visual detection of the measured change in the environment, although electronic read out is also possible when a quantitative result is required. In this type of sensor, a change in the reflected wavelength at a constant angle of observation is due to dimensional change (shrinkage or swelling of the layer) and/or change of the effective refractive index. Depending on the nature of the environmental change causing the response, either the dimensional change can be the prevailing contributor [33], or the change of the effective refractive index [34] is the response determining factor.

The influence of the initial phase difference $\varphi$ between the probe and the diffracted beams introduced by the grating depends on the initial properties of the grating and is defined as

$$
\varphi=\frac{2 \pi \Delta n d}{\lambda_{r} \cos \theta_{B}},
$$

where $\Delta \boldsymbol{n}$ is the refractive index modulation, $\boldsymbol{d}$ is the grating thickness, $\boldsymbol{\theta}_{\boldsymbol{B}}$ is the Bragg angle, and $\boldsymbol{\lambda}_{\boldsymbol{r}}$ is the reconstruction wavelength. The variation of the $\mathrm{DE}$ of a transmission hologram as a result of the variation of the properties of the hologram containing layer due to exposure to the analyte can be determined by Eq. (2) for surface gratings operating in the Raman-Nath regime and Eq. (3) for volume phase gratings: (a)

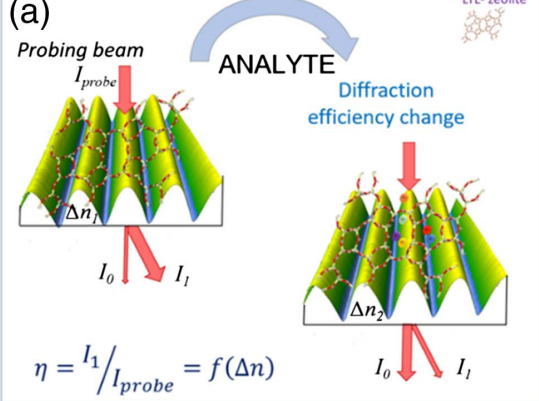

(b)

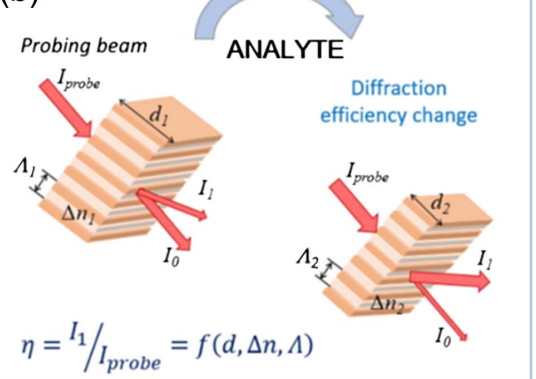

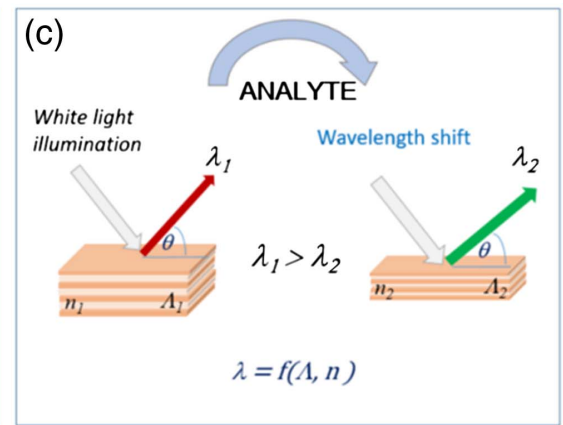

Fig. 1. Schematic presentation of the principle of operation of a holographic sensor based on (a) SRG, (b) volume transmission phase grating, and (c) volume reflection phase grating. 


$$
\begin{gathered}
\frac{\partial(\eta)}{\partial(\varphi)}=\frac{1}{2} J_{1}\left(\frac{\varphi}{2}\right)\left[J_{0}\left(\frac{\varphi}{2}\right)-J_{2}\left(\frac{\varphi}{2}\right)\right], \\
\frac{\partial(\eta)}{\partial(\varphi)}=\sin \left(\frac{\varphi}{2}\right) \cos \left(\frac{\varphi}{2}\right) .
\end{gathered}
$$

The variation of the DE and the spectral response at a fixed angle of detection of a reflection hologram as a result of the variation of the properties of the hologram containing layer due to exposure to the analyte can be determined by Eqs. (4)-(6) correspondingly:

$$
\begin{gathered}
\frac{\partial(\eta)}{\partial(\varphi)}=\tanh \left(\frac{\varphi}{2}\right)\left[1-\tanh ^{2}\left(\frac{\varphi}{2}\right)\right], \\
\frac{\partial\left(\lambda_{r}\right)}{\partial(\Delta n)}=\frac{\pi d}{\tanh ^{-1}(\sqrt{\eta}) \cos \theta_{B}}, \\
\frac{\partial\left(\lambda_{r}\right)}{\partial(d)}=\frac{\pi \Delta n}{\tanh ^{-1}(\sqrt{\eta}) \cos \theta_{B}} .
\end{gathered}
$$

A recent study aiming to identify the theoretically optimum grating structure for sensor development has highlighted the need for careful consideration of the initial sensor design, both for surface relief grating (SRG) [31] and volume grating-based sensors [32]. Holographic sensor design incorporates a wide range of parameters, namely, hologram geometry (i.e., transmission or reflection), thickness, fringe spacing, reconstruction wavelength, and initial grating refractive index modulation; all of which have been shown to significantly influence the sensitivity of the final sensor device. Some constraints on the implementation of this model are inevitable; for example, the initial grating refractive index modulation of SRG-based sensors is limited by the choice of functionalizing material for the target analyte. However, the design and physical parameters of the holographic sensors described in this work have been selected using the aforementioned model to maximize sensor response when possible.

\section{MATERIALS AND METHODS}

\section{A. Materials}

Four different photopolymer compositions were used in this study in order to demonstrate the flexibility of utilizing photopolymers in the fabrication of holographic sensors. Each composition is specially tuned for obtaining optimum properties of the initial holographic diffraction grating used for the fabrication of the sensor. Table 1 shows the chemical composition of photopolymer A used in fabrication of the surface relief structures, photopolymers $\mathrm{B}$ and $\mathrm{C}$ used in the development of the temperature sensor, where photopolymer B is the reference sample, and photopolymer D used in fabrication of pressuresensitive reflection holograms. The chemicals used in the preparation of the photopolymers were purchased from Fisher Scientific and Sigma Aldrich. All of the materials used in this work were of analytical grade without further purification. In order to facilitate the comparison of the photopolymers used in this study, pie charts of the four compositions are shown in Fig. 2. As can be seen from the pie charts, composition A contains the highest percentage of monomers when compared with the other three compositions. The reason for that is that in previous studies it was observed that this facilitates the formation of larger surface amplitudes after post-recording exposure to elevated temperatures [35]. The two compositions B and C differ in the type of monomer used. Composition D contains, in addition to the monomer, a cross-linker, free radical generator, binder, and a sensitizing dye, which are all present in compositions A-C, a chain transfer agent, and a free radical scavenger.

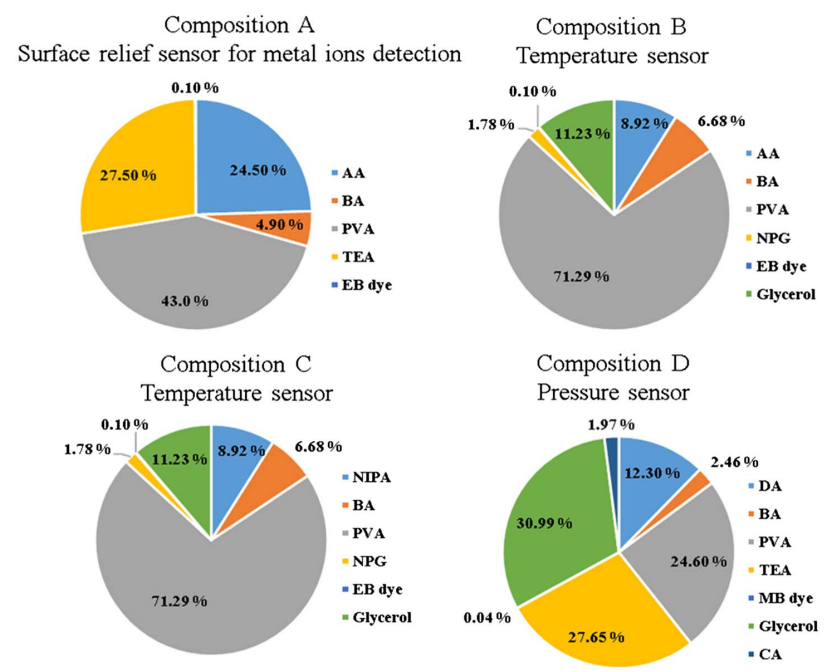

Fig. 2. Chemical composition of the dry photopolymer layers used in fabrication of the holographic sensors.

Table 1. Photopolymer Compositions

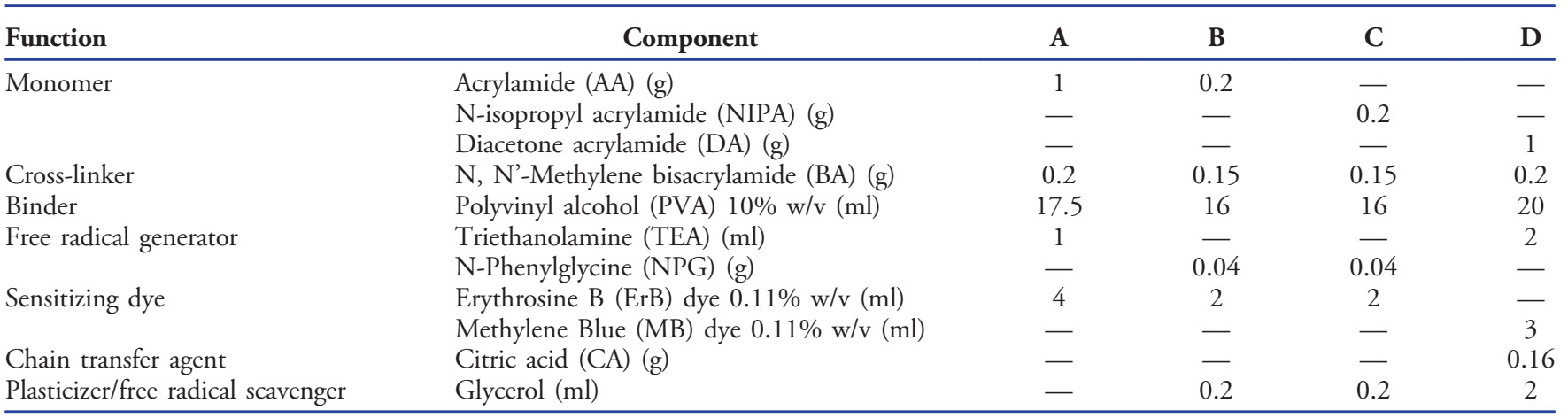




\section{Composition A-Metal Ion Sensor}

An Acrylamide (AA) -based photopolymer with composition A was used to fabricate the SRGs for sensors for metal ion detection. These types of photopolymers and the mechanism of recording in them have been thoroughly studied and reported in the literature [36-41]. Composition A was previously optimized for achieving maximum surface relief amplitude [35]. This required a decrease of the amount of TEA in the layer and an increase of the amount of monomer when compared with AA-based photopolymers typically used $[15,33,40,41]$.

\section{Compositions $B$ and $C$-Temperature Sensor}

For the development of a thermal sensor with memory effect, photopolymers with compositions $\mathrm{B}$ and $\mathrm{C}$ were used. The only difference between them is the main monomer used; all other chemical components are kept constant, as shown in Table 1. The N-isopropylacrylamide (NIPA) -based photopolymer was recently optimized and characterized for holographic recording in both the transmission and reflection modes [22], while the second is a modification of the AA-based photopolymer that has been known for many years [36-41].

\section{Composition D-Pressure Sensor}

Pressure-sensitive holographic structures were developed by holographic patterning of a novel pressure-sensitive photopolymer material [42]. The photopolymer composition D is presented in Table 1. The concentration of the photopolymer components in dry layers is shown in Fig. 2. This composition contains a low toxicity monomer, diacetone acrylamide (DA), which is responsible for the pressure sensitivity of the recorded holograms. In addition, a chain transfer agent (citric acid) and a free radical scavenger (glycerol) are both simultaneously needed in order to achieve high DE in the reflection mode of recording. To obtain $10 \% \mathrm{w} / \mathrm{v}$ polyvinyl alcohol (PVA) stock solution, $10 \mathrm{~g}$ of PVA (molecular weight 9000-10,000, 80\% hydrolyzed) was dissolved in $100 \mathrm{ml}$ deionized (DI) water by magnetic stirring and heating at $75^{\circ} \mathrm{C}$ in open ambient laboratory conditions. Similarly, $0.11 \mathrm{~g}$ of the photosensitive dyes
Erythrosine B and Methylene Blue were dissolved in $100 \mathrm{ml}$ DI water at room temperature by magnetic stirring to prepare the dye solution of the desired concentration $(0.11 \% \mathrm{w} / \mathrm{v})$. During the preparation of photopolymer solutions, the optimized amounts of all of the components, as described in Table 1, were mixed thoroughly with a magnetic stirrer for $2 \mathrm{~h}$ at ambient laboratory conditions [temperature $21 \pm 0.5^{\circ} \mathrm{C}$ and relative humidity $(\mathrm{RH}) 35 \pm 2 \%$ ].

\section{B. Preparation of the Photopolymer Layers} 1. Metal Ion Sensor

A specific volume of photopolymer solution with composition A $(0.3 \mathrm{ml})$ was spread evenly on a glass slide of the dimensions of $7.6 \mathrm{~cm} \times 2.6 \mathrm{~cm}$. The coated glass slide was placed on a leveled surface and allowed to dry in the dark for typically 5-6 h. The thickness of the dry sample was $30 \pm 3 \mu \mathrm{m}$.

\section{Temperature Sensor}

For holographic recording, the layers were separately prepared from both types of polymer solutions with compositions $\mathrm{B}$ and $\mathrm{C}$ by using $1.5 \mathrm{ml}$ of each solution, which was evenly spread over on the microscopic glass slide of the dimensions of $7.6 \mathrm{~cm} \times 2.6 \mathrm{~cm}$. The slides with the polymer layer were placed on a leveled surface and allowed to dry in the dark room for $18-20 \mathrm{~h}$ at $35 \pm 2 \% \mathrm{RH}$ and $21 \pm 0.5^{\circ} \mathrm{C}$. The thickness of the layers was in the range from $88 \pm 7 \mu \mathrm{m}$.

\section{Pressure Sensor}

Photopolymer layers with thicknesses ranging from 125 to $195 \mu \mathrm{m}$ were prepared by deposition of 0.5 to $0.9 \mathrm{ml}$ of photopolymer $\mathrm{D}$ on the leveled glass slides $(7.6 \mathrm{~cm} \times 2.6 \mathrm{~cm})$ and dried for $18 \mathrm{~h}$ in a dark room at ambient temperature of $21 \pm 0.5^{\circ} \mathrm{C}$ and $\mathrm{RH}=35 \pm 2 \%$.

\section{Holographic Recording}

The holographic recording setups for recording transmission and reflection volume phase gratings are shown in Fig. 3. All recording was carried out on an optical table (Newport RS 4000), which was floated in order to provide mechanical

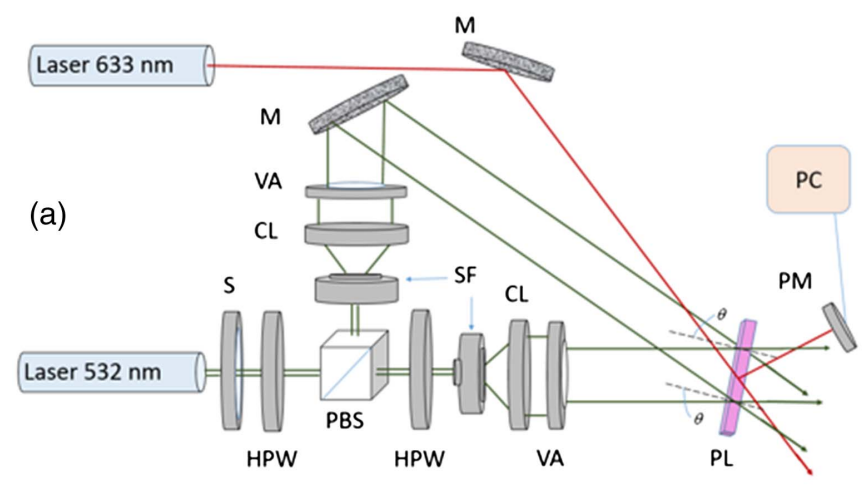

(b)

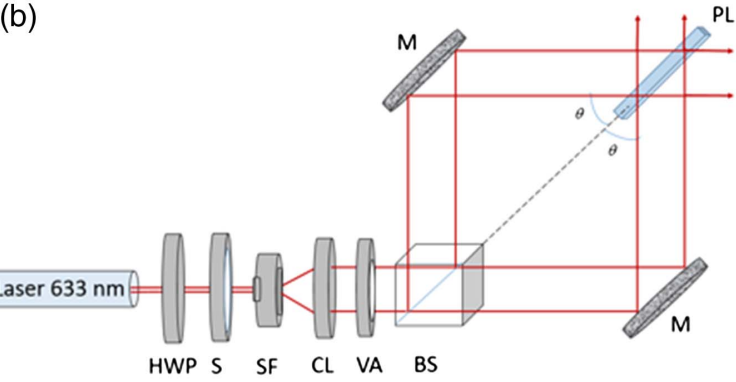

(c)

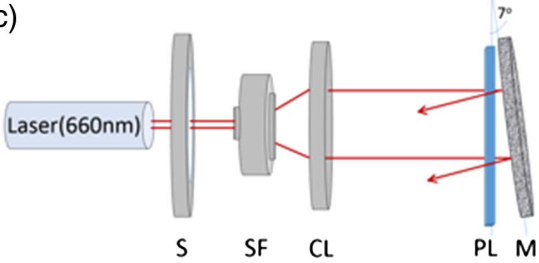

Fig. 3. Experimental setup for holographic recording of (a) transmission and (b), (c) reflection holograms. S, electronic shutter; HWP, half-wave plate; PBS, polarizing beam splitter; SF, spatial filter; CL, collimator; VA, variable aperture; M, mirror; PM, power-meter; PL, photopolymer layer; PC, computer; BS, non-polarizing beam splitter. 
Table 2. Holographic Recording Conditions for the Four Different Photopolymer Compositions

\begin{tabular}{|c|c|c|c|c|c|}
\hline Photopolymer Composition & Recording Geometry & $\begin{array}{l}\text { Spatial Frequency, } \\
\text { Lines }(\mathbf{m m})\end{array}$ & $\begin{array}{l}\text { Recording Intensity } \\
\qquad\left(\mathbf{m W} / \mathbf{c m}^{2}\right)\end{array}$ & $\begin{array}{l}\text { Exposure } \\
\text { Time (sec) }\end{array}$ & Thickness $(\mu \mathrm{m})$ \\
\hline Composition A & Transmission & 300 & 10 & 100 & 30 \\
\hline Composition $\mathrm{C}$ & Transmission & 800 & 3.9 & 100 & 85 \\
\hline \multirow[t]{2}{*}{ Composition D } & Two-beam reflection & 3050 & 3 & 90 & 125 \\
\hline & Denisyuk reflection & 4500 & 10 & 100 & $125-195$ \\
\hline
\end{tabular}

stability of the optical setup. In transmission mode recording [Fig. 3(a)], the photopolymer layers were exposed to two beams of $532 \mathrm{~nm}$ wavelength obtained by splitting a Nd:YVO 4 laser beam. The angle of the recording beams was altered to record the diffraction gratings with the spatial frequency of 300 and 800 lines $/ \mathrm{mm}$. Real time DE growth curves were recorded using a $633 \mathrm{~nm}$ probe beam from a helium-neon $(\mathrm{He}-\mathrm{Ne})$ laser. The intensity of the diffracted beam was monitored by means of an optical power meter (Newport 1830-C), and the acquired data were transferred to a computer. The DE of the transmission gratings was calculated as the ratio of the intensity of the diffracted beam and the intensity of the incident beam. In the reflection mode of recording, both two-beam recording geometry [Fig. 3(b)] and Denisyuk recording geometry [Fig. 3(c)] were used. Reflection gratings with a spatial frequency of 3050 lines/mm were recorded using a $633 \mathrm{~nm} \mathrm{He}-\mathrm{Ne}$ laser beam. Denisyuk reflection gratings with a spatial frequency of 4500 lines $/ \mathrm{mm}$ were recorded at a $660 \mathrm{~nm}$ wavelength using a Cobolt Flamenco 500 laser. Depending on the holographic recording material, different exposure times and recording intensities were used, as specified in Table 2 .

\section{Experimental Testing of the Sensors}

\section{Metal Ion Sensor}

A polarized $\mathrm{He}-\mathrm{Ne}$ laser of wavelength $633 \mathrm{~nm}$ was used as a probe beam incident at the Bragg angle to the grating. The intensity of the first-order diffracted beam was measured using an optical power meter to determine the DE of the recorded gratings. The angular selectivity curve was acquired for each sample. The DE was measured initially before any exposure to analyte solutions. The sensor was then exposed to an analyte solution for $60 \mathrm{~s}$. After that, the sample was dried, and the $\mathrm{DE}$ was remeasured. The sensor was exposed to the analyte solution for another $30 \mathrm{~s}$, and DE was measured; this procedure was repeated to achieve a total exposure of $3 \mathrm{~min}$.

\section{Temperature Sensor}

Temperature sensitivity and response of the recorded photonic structure was studied by exposing the structure to temperatures ranging from $18^{\circ} \mathrm{C}$ to $60^{\circ} \mathrm{C}$, while monitoring the variation in $\mathrm{DE}$. The experimental setup used for the temperature response study is shown in Fig. 4. The holographic grating was placed on the temperature controlled stage (Linkam Model THMS600), and the lid of the cell was closed tightly. The temperature was controlled in the required range by using a temperature controller (Linkam Model TMS 93).

Initially, the temperature of the stage was increased from $18^{\circ} \mathrm{C}$ to $60^{\circ} \mathrm{C}$, then cool air was pumped into the stage with a cooling pump (Linkam Model LNP) to decrease the

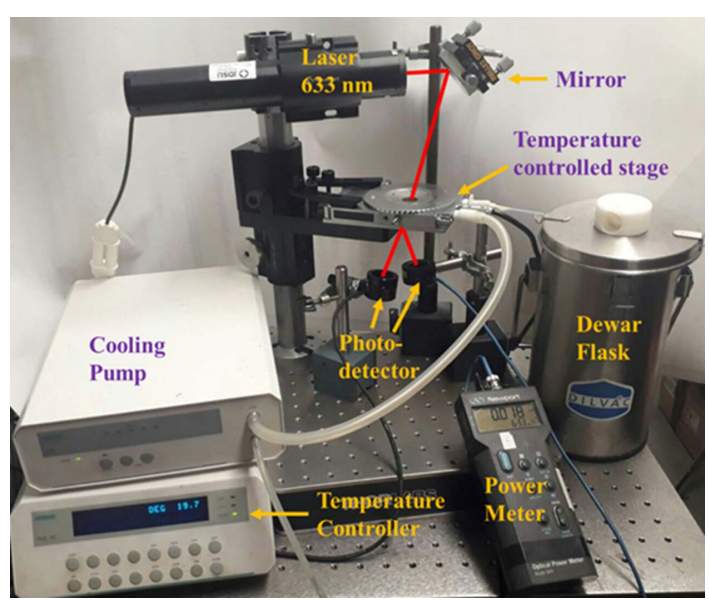

Fig. 4. Setup used in studying temperature response of recorded gratings.

temperature back to $18^{\circ} \mathrm{C}$ for studying the reversibility of the structure.

A dewar flask filled with ice was used to produce the cool air, which was required for decreasing the stage temperature to $18^{\circ} \mathrm{C}$ with a controlled rate of decrease. During the temperature exposure, the changes in the intensity of the first order diffracted beam $\left(I_{1}\right)$ and intensity of the transmitted beam $\left(I_{0}\right)$ were monitored simultaneously by using two optical power meters (Newport Model 840). The DE in this experiment was defined by $I_{1} /\left(I_{1}+I_{0}\right)$.

\section{Pressure Sensor}

Pressure was applied to the reflection gratings using an Instron Series 5569 Tensile Tester. A ball bearing of $3 \mathrm{~mm}$ diameter was attached to the tip of the Instron. Initially, a flat indenter tip was used; however, it proved impossible to apply uniform pressure to the sample using this method. Merlin v. 5.31 software was used to control the downward force $F$ applied to the samples. The Hertzian theory of elastic deformation [43] was used to approximate the maximum contact pressure at the center of the ball bearing $P_{o}$ exerted on the reflection grating:

$$
P_{o}=\frac{3 F}{2 \pi a^{2}},
$$

where the radius of the contact area $\boldsymbol{a}$ was determined from microscope images of the photopolymer sample taken after application of pressure. A $200 \mu \mathrm{m}$ core ultraviolet-visible (UVVis) optical fiber connected to an Avantes AvaLight-Hal-S white light source was used to illuminate the reflection gratings. 
An Avantes AvaSpec 2048-2 spectrometer using a $400 \mu \mathrm{m}$ core UV-Vis optical fiber was used to monitor the spectral response of the holograms before and after application of pressure. A Horiba Jobin Yvon confocal Raman spectrometer operating with a broad white light source and a $900 \mu \mathrm{m}$ diameter pinhole was used to map the reconstruction wavelength as a function of sample position. The spectral measurements were taken $300 \mu \mathrm{m}$ outside the center of the contact area $\boldsymbol{a}$, as the samples were damaged at this point.

Mechanical properties of the pressure-sensitive photopolymer layers were characterized by evaluating the elastic modulus of the material. The compression test was carried out using a materials testing machine (Lloyd Instruments LR30K). Photopolymer layers with thicknesses ranging from 125 to $195 \mu \mathrm{m}$ were under study. A load of $100 \mathrm{~N}$ was applied with a speed of $1 \mathrm{~mm} / \mathrm{min}$ to the photopolymer layers sandwiched between the plastic substrate ( $475 \mu \mathrm{m}$ thick) and a coating film (Melinex Polyester, $50 \mu \mathrm{m}$ thick). The elastic modulus of the composite pressure-sensitive film and substrates was calculated from the linear portion of the load-displacement curves.

\section{EXPERIMENTAL RESULTS AND DISCUSSION}

\section{A. Sensor for Detection of Metal lons}

\section{Functionalization of the Surface Photonic Structures by} Coating with LTL-zeolite Nanoparticles

Following the preparation of the SRG, the layers were characterized using atomic force microscopy (AFM), and the Bragg angle was measured before and after thermal treatment. After this, the SRGs were coated with LTL-type zeolite [44,45] nanoparticles of average size of $40 \mathrm{~nm}$ [Fig. 5(a)] mixed with tetraethyl orthosilicates (TEOS, 98\%) [Fig. 5(b)]. The use of TEOS (sol gel) was necessary in order to stabilize the zeolite nanoparticles in a water environment. Initial studies on the SRG coated with pure zeolite nanoparticles revealed that the layers were destroyed after immersion of the sample in water. The use of sol gel yields a porous matrix that allows pollutants (in this case di-cations), such as copper $\left(\mathrm{Cu}^{+2}\right)$, calcium $\left(\mathrm{Ca}^{+2}\right)$, and $\mathrm{Pb}^{+2}$, to diffuse easily and to interact with the zeolite nanoparticles. This method was tailored in order to detect 1-4 mM metal ions and has previously been demonstrated for $\mathrm{Cu}^{+2}$ ions [26]. A typical composition used for coating of the SRG consisted of TEOS $(24 \mathrm{ml})$, ethanol $(17.5 \mathrm{ml}), 1.5 \%$ $\mathrm{wt} / \mathrm{wt}$ LTL-zeolite suspension $(12 \mathrm{ml})$, and $0.04 \mathrm{M}$ nitric acid $(3 \mathrm{ml})$. The amount of LTL zeolite suspensions was varied between 8 and $15 \mathrm{ml}$ and was optimized at $12 \mathrm{ml}$. The optimization involved finding the maximum amount of zeolite nanoparticles that can be incorporated in a layer with a good optical quality. The solution was stirred for $24 \mathrm{~h}$ and then spincoated at $500 \mathrm{rpm}$ on the pre-recorded surface photonic structure. The samples were left for $24 \mathrm{~h}$ at room temperature before further studies. Next, the gratings were exposed to the different metal ion solutions for pre-determined time intervals. The layers were studied under AFM, and the DE change was measured at different stages. The detailed fabrication process of the surface structures are described elsewhere [35].

\section{Selectivity and Sensitivity Studies}

In order to demonstrate the versatility of the proposed holographic sensor for detection of analytes, the LTL-zeolite-coated SRG was exposed to $\mathrm{Pb}^{+2}$ solutions with $1-4 \mathrm{mM}$ concentration and DI water.

The sensor response to $\mathrm{Pb}^{+2}$ is observed due to the presence of LTL zeolites. In Fig. 5(c), the normalized DE versus exposure time is shown for the LTL-zeolite-coated SRG exposed to
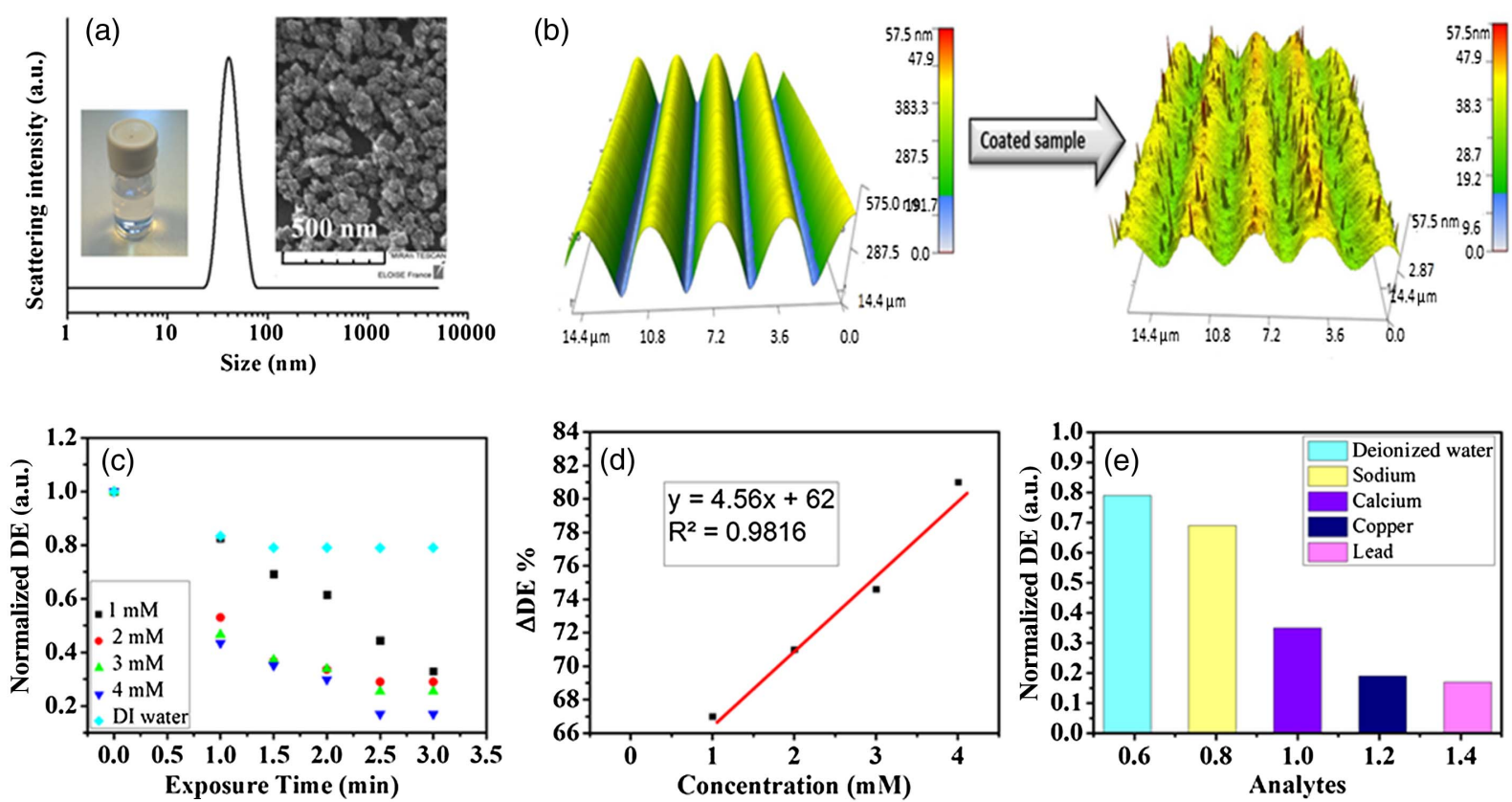

Fig. 5. (a) Dynamic light scattering (DLS) measurement of LTL-zeolite size distribution [inset, photograph and scanning electron microscope (SEM) image of LTL zeolites]; (b) white light surface profiler images of surface grating coated and uncoated with LTL-zeolites; (c) NDE change for LTL zeolitesol-gel-coated photonic structures exposed to $1-4 \mathrm{mM} \mathrm{Pb}^{+2}$; (d) sensitivity of the response at 3 min for $\mathrm{Pb}^{+2}$; (e) comparison of the change in DE to different analytes. 
fresh water and $1-4 \mathrm{mM} \mathrm{Pb}^{+2}$ solutions. Although at shorter exposure times the response is not linear, after a 3 min exposure to the analyte, the DE change depends linearly on the concentration of the analyte, as shown in Fig. 5(d). A sensitivity at 3 min exposure to the $\mathrm{Pb}^{+2}$ analyte $(\mathrm{DE} / \mathrm{mM})$ of $4.56 \%$ / $\mathrm{mM}$ was observed for this sensor [Fig. 5(d)]. The same procedure was used for exposure to $\mathrm{Cu}^{+2}, \mathrm{Ca}^{+2}$, and sodium $\left(\mathrm{Na}^{+1}\right)$. When compared with other metal ions, it can be seen that the sensor is more sensitive to di-cations [Fig. 2(e)]. It is clear that the sensor is less responsive to $\mathrm{Na}^{+}$as compared to $\mathrm{Ca}^{+2}, \mathrm{Cu}^{+2}$, and $\mathrm{Pb}^{+2}$. The selectivity of the response to dications can be attributed to the LTL-nanoparticles, since they have diverse responses for different oxidation states [45,46]; it was observed that they were more responsive to +2 oxidation states, as compared to the other oxidation states. The results were repeated three times and show good reproducibility and repeatability.

The advantage of the proposed technology platform for preparation of sensors is its flexibility, because the selectivity can be easily changed by changing the functionalizing layer chemical structure. The loadings of the analyte-sensitive materials can be tailored. Due to the fact that it is a surface sensor, the sensor also has a fast response time, which allows for real time monitoring. It uses low cost materials, thus it is suitable for fabrication of disposable holographic sensors that change their properties on exposure to the analyte. It is important to mention the limitations of this type of sensor. A major limitation is the dynamic range, since the maximum DE of SRGs is limited to $33 \%$, whereas in volume gratings the dynamic range is much larger, and the DE can approach $100 \%$. On the other hand, utilizing surface structures provides for faster response due to the shorter analyte diffusion depths that are required when compared to the volume structures.

\section{B. Temperature Sensor}

Volume transmission phase gratings recorded in photopolymer compositions $\mathrm{B}$ and $\mathrm{C}$ were studied to demonstrate control over the temperature response of the holographic sensor and how it can be used in development of a practical optical device indicating exposure to elevated temperature. Previous work was focused on the development of the NIPA-based photopolymer for temperature sensing [20,22]; however, this study looks in detail at the effect of a prolonged duration of time spent at elevated temperatures on DE. This could be useful in the transportation of goods, for example, where specific products, such as food or pharmaceutical products, may be damaged by exposure to elevated temperature, and it may be useful for the goods' supply chain to have knowledge of this event.

\section{Holographic Recording of Temperature Sensors}

Real time DE growth curves of the recorded gratings are shown in Fig. 6(a). After recording, gratings were bleached with UV light for $100 \mathrm{~s}$ to polymerize the remaining monomers left in the layer by using a UV exposure intensity of $60 \mathrm{~mW} / \mathrm{cm}^{2}$ provided by Dymax UV-curing system (model ECE-200). In this experiment, $\mathrm{DE}$ was calculated as the ratio of the diffracted-beam intensity $\left(I_{d}\right)$ and the incident-beam intensity $\left(I_{i}\right)$. Bragg selectivity curves of the diffracted beam were acquired through LabVIEW software before and after the
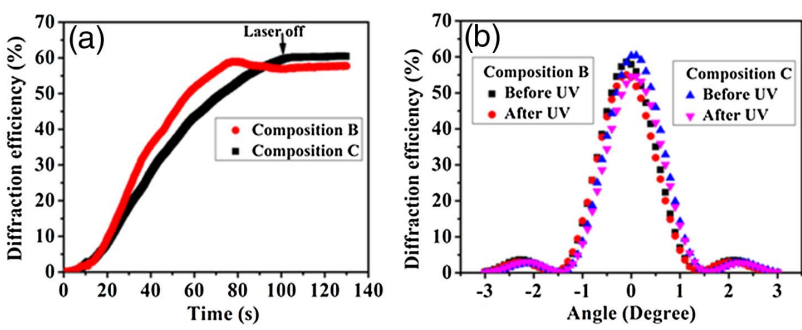

Fig. 6. (a) Real time growth curve of DE and (b) Bragg selectivity curve of DE before and after UV-curing for compositions B and C.

UV-curing, as shown in Fig. 6(b). Only a small decrease (within $5 \%$ range) in DE was observed after UV-curing. This indicates that the recorded grating is mainly due to density changes caused by concentration gradient driven monomer diffusion, which occurs during the holographic recording process. This effect is well-documented for AA/PVA photopolymer systems and has been reported previously $[41,47,48]$.

\section{Investigation of the Effect of Temperature Variation on the Holographic Grating DE.}

The effect of temperature variation on the DE of volume transmission gratings was studied in the temperature range of $18^{\circ} \mathrm{C}-60^{\circ} \mathrm{C}$, using the experimental setup shown in Fig. 4. In the first half-cycle, temperature was increased at rate of $10^{\circ} \mathrm{C} / \mathrm{min}$ from $18^{\circ} \mathrm{C}$ to $60^{\circ} \mathrm{C}$ and decreased back to $18^{\circ} \mathrm{C}$ in the next half-cycle at a rate of $5^{\circ} \mathrm{C} / \mathrm{min}$ in the reversed direction. Temperature dependant response of the NIPA-based and AA-based gratings is shown in Fig. 7. Figure 7(a) shows change in normalized DE (NDE) when the temperature of the stage was decreased immediately after reaching $60^{\circ} \mathrm{C}$, while Fig. $7(\mathrm{~b})$ shows the NDE change when the stage was left for $20 \mathrm{~min}$ at $60^{\circ} \mathrm{C}$. The NDE was defined as the ratio of the DE at the current temperature and the $\mathrm{DE}$ at the start of the experiment at $18^{\circ} \mathrm{C}$.
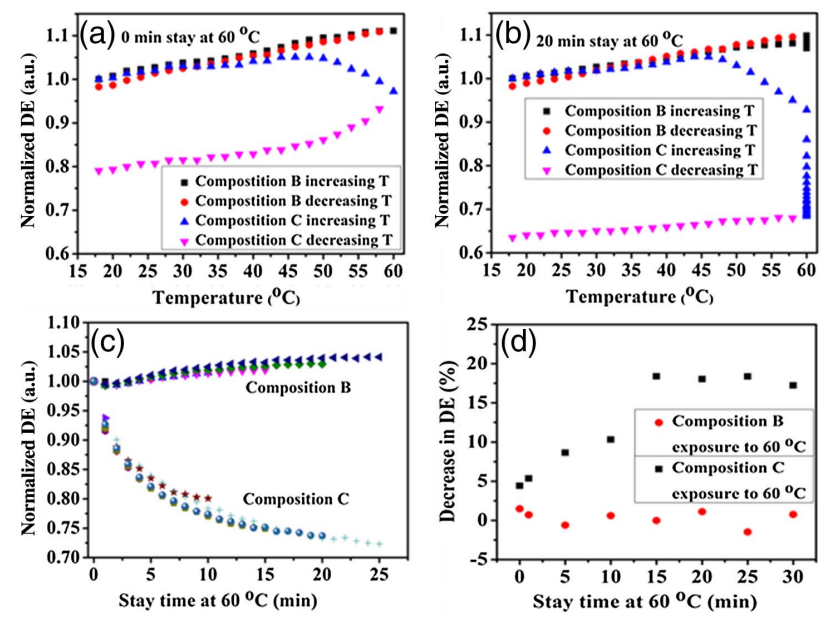

Fig. 7. Normalized DE versus temperature for AA-based and NIPA-based gratings: (a) temperature of the stage was decreased immediately after reaching $60^{\circ} \mathrm{C}$, (b) temperature of the stage was kept at $60^{\circ} \mathrm{C}$ for $20 \mathrm{~min}$, (c) NDE versus exposure time at $60^{\circ}$, and (d) decrease in DE versus exposure time at $60^{\circ} \mathrm{C}$. 
During increasing temperature, it is clearly seen from the results shown in Fig. 7 that the NDE of both NIPA-based and AA-based gratings increases similarly with increasing temperature up to $45^{\circ} \mathrm{C}$. Above $45^{\circ} \mathrm{C}$ NIPA-based gratings abruptly show a decrease in NDE, while AA-based gratings continue the increase in NDE and, thus, the completely opposite behavior is observed for NIPA-based and AA-based gratings above $45^{\circ} \mathrm{C}$ at the mentioned increasing temperature rate of $10^{\circ} \mathrm{C} / \mathrm{min}$.

For the NIPA-based gratings, such change of the NDE with the increasing temperature can be attributed to the switching character of Poly(NIPA) (PNIPA) from the hydrophilic to the hydrophobic phase. PNIPA is a well-known thermo-responsive polymer that has phase transition capability at a lower critical solution temperature (LCST) existing at about $32^{\circ} \mathrm{C}$ for pure PNIPA; however, this transition temperature can be manipulated by copolymerization with other appropriate monomers [49,50]. As previously described in Ref. [51], in this case, the polymer is only in the hydrophilic state, as the actual polymer layer does not achieve the LCST of PNIPA quickly enough until the stage temperature reaches to $45^{\circ} \mathrm{C}$. So, NDE increases as the layer absorbs water molecules from air, and this causes a swelling of the layer. An increase of the refractive index modulation due to the different absorption of water in the bright and dark fringe areas is also possible. Above $45^{\circ} \mathrm{C}$, the polymer achieves LCST, and NDE reaches saturation. With a further increase of temperature until $60^{\circ} \mathrm{C}$, the PNIPA is in the hydrophobic state and expels water molecules from the PNIPA rich areas; this causes shrinkage and decreases the refractive index modulation, which leads to a decrease in the NDE [22].

In the case of AA-based gratings, no such phenomena of hydrophilic and hydrophobic phase transition is observed with temperature changes, and the continuous increase in NDE for AA-based gratings can be attributed to a change in the refractive index modulation or thickness of the polymer layer.

During the reversed half-cycle from $60^{\circ} \mathrm{C}-18^{\circ} \mathrm{C}$, NDE is decreasing for both NIPA-based and AA-based gratings. For NIPA-based gratings, the NDE decrease is possibly due to the fact that the actual polymer temperature is still above the LCST of the PNIPA, due to which it continues to expel water molecules. In order to check this hypothesis, the layers were left at $60^{\circ} \mathrm{C}$ for a longer time duration. Figure 7 (b) shows the measured NDE when the layers were left for $20 \mathrm{~min}$ at $60^{\circ} \mathrm{C}$. With temperature decrease, the NDE of AA-based gratings decreases and achieves a value at $18^{\circ} \mathrm{C}$ with some differences compared to the original diffraction at this temperature. Thus, the hologram has a memory of the exposure to elevated temperature. The next step was to study how the memory effect depends on the time spent at elevated temperature.

\section{Effect of the Time of Exposure to Elevated Temperature and Reversibility/Irreversibility of the Change in the Initial DE The effect of elevated temperature on the NDE of gratings for different exposure times was studied by exposing the photonic structure to $60^{\circ} \mathrm{C}$. The dependence of NDE on exposure time at $60^{\circ} \mathrm{C}$ is shown in Fig. 7(c). The temperature controller was used to keep the samples' temperature constant while varying the exposure time in the range of $0-25 \mathrm{~min}$. Clearly, for a constant exposure temperature at $60^{\circ} \mathrm{C}$, the response of the}

NIPA- and AA-based gratings is opposite, as indicated by the variation in their NDE values. For NIPA-based gratings, it shows a sharp decrease in NDE and seems to be approaching saturation for a longer exposure time of $20 \mathrm{~min}$, while for AAbased gratings, NDE shows a slight, gradual increase with saturation value achieved in 15 min exposure time. As shown in Fig. 7(d), it was also observed that for NIPA-based gratings the irreversibility of the temperature-induced changes depends on the duration of the time spent at temperatures above the LCST of the PNIPA. The irreversible changes in the DE of NIPAbased gratings increase with increasing exposure time at $60^{\circ} \mathrm{C}$ and reach a saturation value with up to $20 \%$ irreversible decrease observed in $15 \mathrm{~min}$ exposure time, while AA-based gratings show reversibility within $2 \%$. From the linear section of Fig. 7(d) (i.e., up to $15 \mathrm{~min}$ ), one can conclude that the rate of decrease in $\mathrm{DE}$ is $1 \% / \mathrm{min}$. This provides a straightforward estimate of the time the sensor has spent at $60^{\circ} \mathrm{C}$.

As can be seen from the results, one of the main benefits of volume transmission gratings is that they offer a larger dynamic range in comparison to surface gratings, and, by using real time monitoring of the recording process, it is possible to choose an initial DE that will facilitate operation in an approximately linear regime. The initial DE in this case was $60 \%$. The main challenge in the development of the temperature sensor is the relatively small changes in DE. It may be possible to improve the response by choosing slanted, instead of unslanted, transmission gratings. Another limitation of the studied sensor is that the sample cannot be covered by a protective layer, since PNIPA's temperature response is based on water being expelled at elevated temperatures and re-absorbed at lower temperatures. Thus, water has to have access to the photopolymer layer. One may also argue that the sensor is open to interference from other conditions in the environment, such as humidity. However, the humidity response of the layer has been previously studied and shown to be negligible in this temperature range $[21,52]$.

\section{Pressure Sensor}

Pressure testing was carried out as described in Section 3.D. Figure 8(a) shows a schematic of the testing: a $3 \mathrm{~mm}$ diameter ball bearing was used to exert known forces $F$ on the photopolymer-based reflection gratings. A value for the radius of the contact area, $a=35 \mu \mathrm{m}$, was determined by microscopy, as shown in the inset, and used for the calculations of contact pressure. Volume phase reflection gratings were recorded in composition $\mathrm{D}$ for pressure testing using two methods. The data shown in Figs. 8(b)-8(e) were obtained for gratings recorded using a $633 \mathrm{~nm} \mathrm{He}-\mathrm{Ne}$ laser configured in a standard two-beam reflection geometry at 3050 lines $/ \mathrm{mm}$ with recording conditions of $90 \mathrm{~s}$ exposure time and $3 \mathrm{~mW} / \mathrm{cm}^{2}$. The DE of the recorded gratings reached a maximum of $50 \%$; the optimization of the recording conditions for composition $\mathrm{D}$ is described in detail in Ref. [42]. The recording wavelength was later modified from 633 to $660 \mathrm{~nm}$, as this wavelength is closer to the maximum absorbance of the photopolymer composition sensitized with Methylene Blue. While this was not observed to significantly enhance the holographic performance of composition D, it does improve the dynamic range of a holographic pressure sensor, which is blue shifted 

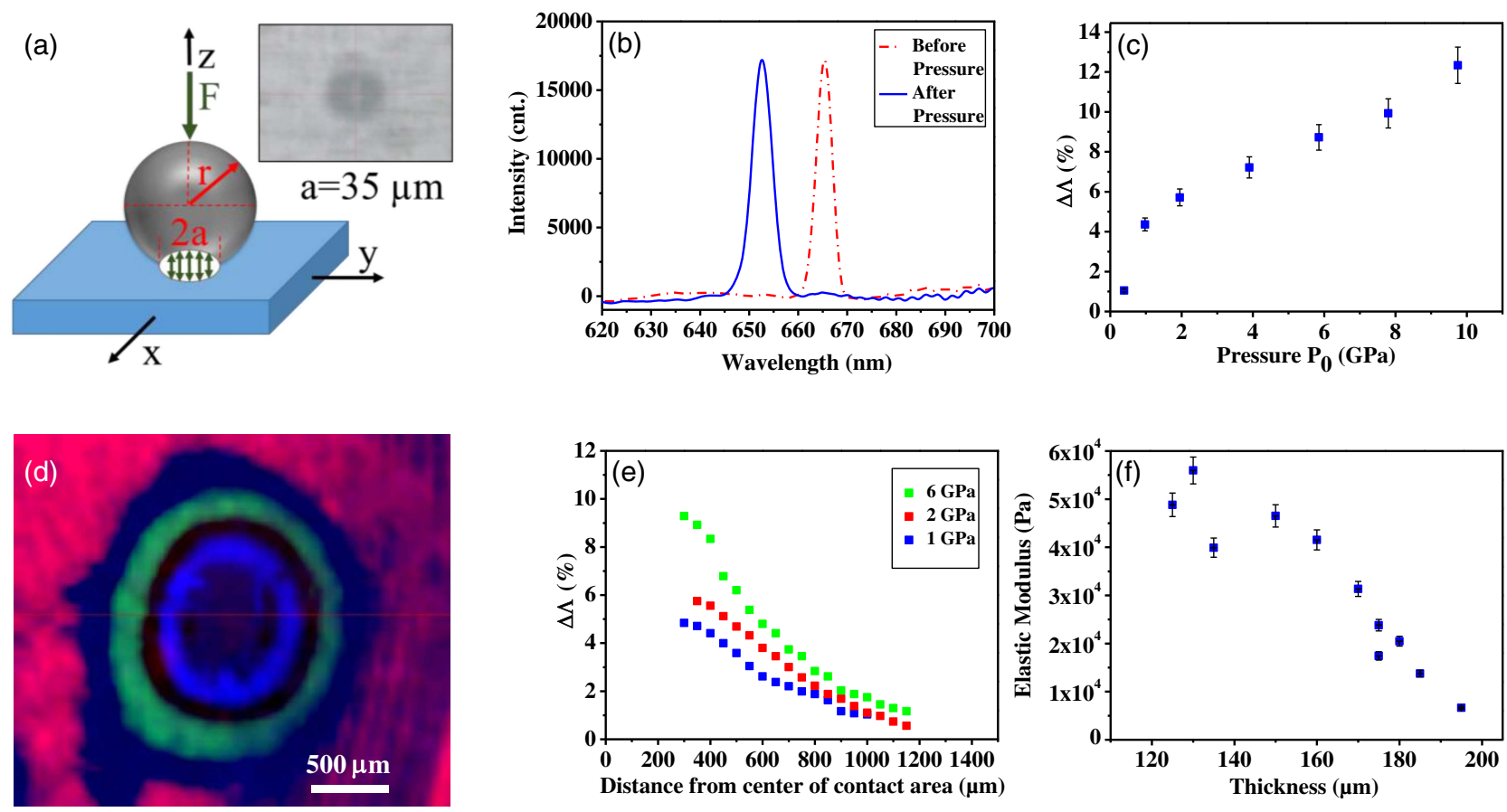

Fig. 8. (a) Schematic of pressure testing with ball bearing $r=1.5 \mathrm{~mm}, a=35 \mu \mathrm{m}$; (b) spectra of reconstructed wavelength of a reflection grating before and after application of pressure; (c) percent change in hologram fringe spacing $(\Delta \Lambda)$ versus pressure (GPa); (d) $2 \mathrm{D}$ color map of $\Delta \Lambda$ for $P_{o}=1 \mathrm{GPa}$; (e) $\Delta \Lambda$ as a function of distance from the center the of contact area $(\mu \mathrm{m})$ for $P_{o}=1,2$ and $6 \mathrm{GPa}$; (f) elastic modulus (Pa) versus reflection grating thickness $(\mu \mathrm{m})$.

with increasing pressure, as the initial reconstruction wavelength is shifted from 633 to $660 \mathrm{~nm}$. The data and images in Figs. 8(f) and 9 were obtained for reflection gratings recorded with a Denisyuk geometry at a $660 \mathrm{~nm}$ wavelength using a Cobolt Flamenco 500 laser with recording conditions of $100 \mathrm{~s}$ exposure time and $10 \mathrm{~mW} / \mathrm{cm}^{2}$. In order to prevent the degradation of the DE over time [42], the samples were UV-cured immediately after recording by exposing them to $17.6 \mathrm{~J} / \mathrm{cm}^{2}$ using a UVlight-curing flood lamp system (Dymax ECE 200). UV-curing provided polymerization of all residual monomers and fixing of the recorded photonic structure.

Figure 8(b) shows an example of the typical change in the spectral response of the grating as a result of application of pressure; the peak reconstruction wavelength is blue shifted due to compression of the reflection grating fringes in accordance with Eq. (6). The percent reduction in the grating fringe spacing $\Delta \Lambda$ is observed to increase by $1 \%-12 \%$ as $P_{o}$ is increased from $0.4-10 \mathrm{GPa}$, as is clearly visible in Fig. 8(c). A pressure

(a)
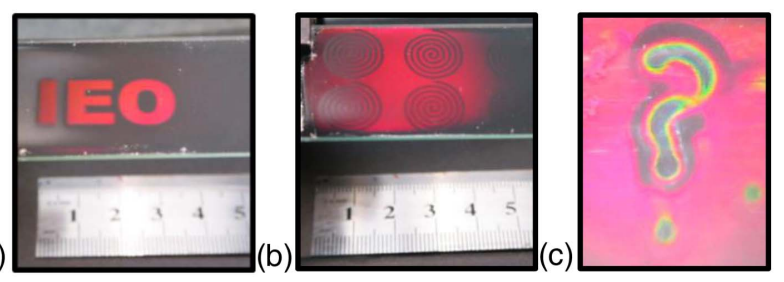

Fig. 9. Example of reflection holograms recorded in composition D: (a) and (b) different shapes of the reflection holograms, (c) after application of pressure with a rubber stamp. sensitivity of $7 \mathrm{~nm} / \mathrm{GPa}$ can be estimated; however, this is based on the central contact pressure $P_{o}$, which is $300 \mu \mathrm{m}$ from the point of spectral measurement, as discussed in Section 2.D, and therefore will significantly underestimate the sensitivity of the device. Figure 8(d) shows a two-dimensional (2D) map of $\Delta \Lambda$ as a function of position from the central point of the contact area for $P_{o}=1 \mathrm{GPa}$. The shift in $\Delta \Lambda$ is at a maximum close to the central contact point, as indicated by the blue color; $\Delta \Lambda$ then decreases as the outward distance is increased, represented by green in the image. A more detailed and quantitative look at $\Delta \Lambda$ as a function of distance is shown in Fig. 8(e) for a single one-dimensional (1D) slice for applied pressures of 1,2, and $6 \mathrm{GPa}$. The effectiveness of the holographic pressure sensor for quantitative and precise pressure mapping is clearly demonstrated.

As discussed in Section 2, there are many physical parameters that influence the sensitivity of a sensor. For a pressuresensitive device, elasticity is a crucial parameter, as it defines the ability of the material to deform under pressure. Figure 8(f) shows a characterization of the influence of hologram thickness on the elastic modulus. By increasing the hologram thickness from $110-195 \mu \mathrm{m}$, the elasticity is seen to decrease. This demonstrates the possibility of tuning the response of the pressure sensor by manipulation of the grating thickness. Some examples of pressure-sensitive reflection holograms recorded in composition D are shown in Fig. 9. Holograms can be readily recorded in a variety of patterns and configurations as well as simple gratings by the incorporation of masks and spatial light modulators (SLMs) in the recording setup. This lends itself to display holography in general, and specifically, for 
the pressure-sensitive feature, document authentication holograms, where pressure-induced color change of a logo or brand recognition feature may be desirable. It is envisaged that pressure-sensitive holograms can be overlaid onto passports, identification (ID) cards, property deeds, certificates of authenticity, diplomas, etc., as an overt security feature allowing for immediate visual authentication.

Photopolymer-based holographic pressure sensors offer several distinct advantages: they offer an immediate, easy to interpret visual readout; they are capable of providing both qualitative and quantitative pressure data; tunability of the response to pressure is possible through variation of the photopolymer devices' elastic properties. The limitation lies mainly in the fact that the range of pressures to which the holographic device is currently sensitive is relatively narrow. More generally, achievement of high DE reflection holograms with robust photopolymers remains challenging and must be addressed.

\section{CONCLUSIONS}

The examples of holographic sensors developed and characterized in this paper demonstrate the flexibility of the approach utilizing self-processing photopolymers for their fabrication. By varation of the composition of the photopolymer or by coating the holographically recorded photopolymer photonic device, one can achive the desired functionality. Sensors based on SRGs coated with LTL zeolite containing nanoparticles are shown to change their $\mathrm{DE}$ in the presence of metal ions. These devices are found to be selective to di-cations, and very little sensitivity is registered to mono-cations due to the nature of the nanoparticles used in the coating layer. The proposed sensor arrangement can be used as a platform for development of a variety of sensors, which can be achieved by simply substituting the functionalizing coating layer. It has been demonstrated that substitution of the monomer AA with NIPA facilitates the recording of holograms that exibit memory of its exposure to elevated temperatures above $45^{\circ} \mathrm{C}$. Such devices can find application in the transport of goods as an indicator for exposure to elevated temperatures. Finally, we have demonstrated how a reflection hologram can be utilized as a pressure sensor for mapping of the applied pressure. This is possible due to the variation of the photopolymer composition that allows for recording of bright, stable reflection holograms with up to $50 \% \mathrm{DE}$.

Funding. Enterprise Ireland (CF/2015/0076P, CF-20170648-P).

Acknowledgment. Muhammad Irfan and Sabad-e Gul acknowledge the support by the DIT Fiosraigh Postgraduate Scholarship Fund. We thank the FOCAS Institute, DIT for the use of core equipment and facilities.

D. Cody contributed to Sections 2, 3.A, 4.C and wrote Section 3.B. S. Gul contributed to Sections 2, 3 composition A, wrote Section 4.A. M. Irfan contributed to Section 3 composition B and composition C, Section 4.B. T. Mikulchyk wrote Section 3.C, contributed to Sections 2, 3.D, 4.C. A. Kharchenko and K. Goldyn synthesized the LTL nanoparticles. S. Mintova and J. Cassidy participated in the design of the experiment and analysis of the results in Section 4.A. S. Martin contributed to the design of the experiments and discussions of the results in Sections 4.A and 4.B and edited the document. I. Naydenova participated in the design of all experiments presented in the paper, designed the article, wrote Section 1, conclusions, contributed to Section 2, and edited the paper.

\section{REFERENCES}

1. R. Caputo, A. De Luca, L. De Sio, L. Pezzi, C. Umeton, A. Veltri, R. Asquini, A. d'Alessandro, D. Donisi, R. Beccherelli, A. V. Sukhov, and N. V. Tabiryan, "POLICRYPS: a liquid crystal composed nano/ microstructure with a wide range of optical and electro-optical applications," J. Opt. A 11, 024017 (2009).

2. L. V. Natarajan, C. K. Shepherd, D. M. Brandelik, R. L. Sutherland, S. Chandra, V. P. Tondiglia, D. Tomlin, and T. J. Bunning, "Switchable holographic polymer-dispersed liquid crystal reflection gratings based on thiol-ene photopolymerization," Chem. Mater. 15, 2477-2484 (2003).

3. A. K. Yetisen, I. Naydenova, F. Da Cruz Vasconcellos, J. Blyth, and C. R. Lowe, "Holographic sensors: three-dimensional analytesensitive nanostructures and their applications," Chem. Rev. 114, 10654-10696 (2014).

4. R. B. Millington, A. G. Mayes, J. Blyth, and C. R. Lowe, "A holographic sensor for proteases," Anal. Chem. 67, 4229-4233 (1995).

5. S. Kabilan, A. J. Marshall, F. K. Sartain, M. C. Lee, A. Hussain, X. Yang, J. Blyth, N. Karangu, K. James, J. Zeng, D. Smith, A. Domschke, and C. R. Lowe, "Holographic glucose sensors," Biosens. Bioelectron. 20, 1602-1610 (2005).

6. E. Vezouviou and C. R. Lowe, "A near infrared holographic glucose sensor," Biosens. Bioelectron. 68, 371-381 (2015).

7. A. G. Mayes, J. Blyth, M. Kyröläinen-Reay, R. B. Millington, and C. R. Lowe, "A holographic alcohol sensor," Anal. Chem. 71, 3390-3396 (1999).

8. A. G. Mayes, J. Blyth, R. B. Millington, and C. R. Lowe, "Divalent metal ion-sensitive holographic sensors," Anal. Chim. Acta 74, 3649-3657 (2002).

9. J. L. Martínez-Hurtado, C. A. Davidson, J. Blyth, and C. R. Lowe, "Holographic detection of hydrocarbon gases and other volatile organic compounds," Langmuir 26, 15694-15699 (2010).

10. E. Leite, I. Naydenova, S. Mintova, L. Leclercq, and V. Toal, "Photopolymerisable nanocomposites for holographic recording and sensor application," Appl. Opt. 49, 3652-3660 (2010).

11. D. Cody, E. Mihaylova, L. O'Neill, T. Babeva, H. Awala, R. Retoux, S. Mintova, and I. Naydenova, "Effect of zeolite nanoparticles on the optical properties of diacetone acrylamide-based photopolymer," Opt. Mater. 37, 181-187 (2014).

12. I. Naydenova, J. Grand, T. Mikulchyk, S. Martin, V. Toal, V. Georgieva, S. Thomas, and S. Mintova, "Hybrid sensors fabricated by inkjet printing and holographic patterning," Chem. Mater. 27, 6097-6101 (2015).

13. G. Bianco, M. A. Ferrara, F. Borbone, F. Zuppardi, A. Roviello, V. Striano, and G. Coppola, "Volume holographic gratings as optical sensor for heavy metal in bathing waters," Proc. SPIE 9506, 95062B (2015).

14. K. Zhou, Y. Geng, H. Liu, S. Wang, D. Mao, and D. Yu, "Improvement of holographic sensing response in substrate-free acrylamide photopolymer," Appl. Opt. 56, 3714-3724 (2017).

15. I. Naydenova, J. Raghavendra, V. Toal, and S. Martin, "A visual indication of environmental humidity using a color changing hologram recorded in a self-developing photopolymer," Appl. Phys. Lett. 92, 031109 (2008).

16. H. Liu, D. Yu, K. Zhou, D. Mao, L. Liu, H. Wang, W. Wang, and Q. Song, "Temperature-induced spectrum response of volume grating as an effective strategy for holographic sensing in acrylamide polymer part I: sensing," Appl. Opt. 55, 9907-9916 (2016).

17. M. Zawadzka, T. Mikulchyk, D. Cody, S. Martin, A. K. Yetisen, H. B. J. L. Martinez-Hurtado, E. Mihaylova, H. Awala, S. Mintova, S. H. Yun, and I. Naydenova, Photonic Materials for Sensing, Biosensing and Display Devices (2016), Vol. 229. 
18. D. Mao, Y. Geng, H. Liu, K. Zhou, L. Xian, and D. Yu, "Two-way shift of wavelength in holographic sensing of organic vapor in nanozeolites dispersed acrylamide photopolymer," Appl. Opt. 55, 6212-6221 (2016)

19. D. Yu, H. Liu, D. Mao, Y. Geng, W. Wang, L. Sun, and J. Lv, "Enhancement of spectrum strength in holographic sensing in nanozeolites dispersed acrylamide photopolymer," Opt. Express 23, 29113-29126 (2015).

20. H. Liu, D. Yu, K. Zhou, S. Wang, S. Luo, W. Wang, and Q. Song, "Improvement of temperature-induced spectrum characterization in a holographic sensor based on $\mathrm{N}$-isopropylacrylamide photopolymer hydrogel," Appl. Opt. 56, 9006-9013 (2017).

21. T. Mikulchyk, J. Walshe, D. Cody, S. Martin, and I. Naydenova, "Humidity and temperature induced changes in the diffraction efficiency and the Bragg angle of slanted photopolymer-based holographic gratings," Sens. Actuators B 239, 776-785 (2017).

22. T. Mikulchyk, S. Martin, and I. Naydenova, "N-isopropylacrylamidebased photopolymer for holographic recording of thermosensitive transmission and reflection gratings," Appl. Opt. 56, 6348-6356 (2017).

23. M. Yan and A. Kapua, "Fabrication of molecularly imprinted polymer microstructures," Anal. Chim. Acta 435, 163-167 (2001)

24. Y. Fuchs, O. Soppera, A. G. Mayes, and K. Haupt, "Holographic molecularly imprinted polymers for label-free chemical sensing," Adv. Mater. 25, 566-570 (2013).

25. Y. Fuchs, S. Kunath, O. Soppera, K. Haupt, and A. G. Mayes, "Molecularly imprinted silver-halide reflection holograms for label-free opto-chemical sensing," Adv. Funct. Mater. 24, 688-694 (2014).

26. S. E. Gul, D. Cody, A. Kharchenko, S. Martin, S. Mintova, J. Cassidy, and I. Naydenova, "LTL type nanozeolites utilized in surface photonics structures for environmental sensors," Microporous Mesoporous Mater. 261, 268-274 (2018).

27. A. K. Yetisen, H. Butt, T. Mikulchyk, R. Ahmed, Y. Montelongo, M. Humar, N. Jiang, S. Martin, I. Naydenova, and S. H. Yun, "Colorselective 2.5D holograms on large-area flexible substrates for sensing and multilevel security," Adv. Opt. Mater. 4, 1589-1600 (2016).

28. G. Ye, X. Li, and X. Wang, "Diffraction grating of hydrogel functionalized with glucose oxidase for glucose detection," Chem. Commun. 46 , 3872-3874 (2010).

29. V. K. S. Hsiao, J. R. Waldeisen, Y. Zheng, P. F. Lloyd, J. Bunning, and T. J. Huang, "Aminopropyltriethoxysilane (APTES)-functionalized nanoporous polymeric gratings: fabrication and application in biosensing," J. Mater. Chem. 17, 4896-4901 (2007).

30. I. Naydenova and V. Toal, "Nanoparticle doped photopolymers for holographic applications," in Ordered Porous Solids, V. Valtchev, S. Mintova, and M. Tsapatsis, eds. (Elsevier, 2009), pp. 559-590.

31. D. Cody and I. Naydenova, "Theoretical modeling and design of photonic structures in zeolite nanocomposites for gas sensing part I: surface relief gratings," J. Opt. Soc. Am. A 34, 2110-2119 (2017).

32. D. Cody and I. Naydenova, "Theoretical modeling and design of photonic structures in zeolite nanocomposites for gas sensing part II: volume gratings," J. Opt. Soc. Am. A 35, 12-19 (2018).

33. I. Naydenova, R. Jallapuram, V. Toal, and S. Martin, "Characterisation of the humidity and temperature responses of a reflection hologram recorded in acrylamide-based photopolymer," Sens. Actuators B 139, 35-38 (2009).

34. H. Liu, D. Yu, K. Zhou, D. Mao, L. Liu, H. Wang, W. Wang, and Q. Song, "Temperature-induced spectrum response of a volume grating as an effective strategy for holographic sensing in an acrylamide polymer part II: physical mechanism," Appl. Opt. 55, 9917-9924 (2016).
35. K. Trainer, K. Wearen, D. Nazarova, I. Nadenova, and V. Toal, "Optimisation of an acrylamide-based photopolymer system for holographic inscription of surface patterns with sub-micron resolution," J. Opt. 12, 124012 (2010).

36. Y. Qi, H. Li, J. Guo, M. R. Gleeson, and J. T. Sheridan, "Material response of photopolymer containing four different photosensitizers," Opt. Commun. 320, 114-124 (2014).

37. S. Blaya, A. Murciano, P. Acebal, L. Carretero, M. Ulibarrena, and A. Fimia, "Diffraction gratings and diffusion coefficient determination of acrylamide and polyacrylamide in sol-gel glass," Appl. Phys. Lett. 84, 4765-4767 (2004).

38. C. Neipp, A. Belendez, S. Gallego, M. Ortuno, I. Pascual, and J. T. Sheridan, "Angular responses of the first and second diffracted orders in transmission diffraction grating recorded on photopolymer material," Opt. Express 11, 1835-1843 (2003).

39. C. Garcia, A. Fimia, and I. Pascual, "Holographic behavior of a photopolymer at high thicknesses and high monomer concentrations: mechanism of photopolymerization," Appl. Phys. B 72, 311-316 (2001).

40. S. Martin, C. A. Feely, and V. Toal, "Holographic recording characteristics of an acrylamide-based photopolymer," Appl. Opt. 36, 57575768 (1997)

41. T. Babeva, I. Naydenova, D. Mikul, S. Martin, and V. Toal, "Two-way diffusion model for short-exposure holographic grating formation in acrylamide based photopolymer," J. Opt. Soc. Am. B 27, 197-203 (2010).

42. D. Cody, S. Gribbin, E. Mihaylova, and I. Naydenova, "Low-toxicity photopolymer for reflection holography," ACS Appl. Mater. Interface 8, 18481-18487 (2016).

43. K. L. Johnson, Contact Mechanics (Cambridge University, 1985).

44. M. Hflzl, S. Mintova, and T. Bein, "Colloidal LTL zeolite synthesized under microwave irradiation," Stud. Surf. Sci. Catal. 158, 11-18 (2005).

45. A. Kharchenko, O. I. Lebedev, V. Zholobenko, V. de Waele, and S. Mintova, "Formation of copper nanoparticles in LTL nanosized zeolite: kinetics study," Phys. Chem. Chem. Phys. 120, 26300-26308 (2016).

46. J. Kecht, Z. Tahri, V. De Waele, M. Mostafavi, S. Mintova, and T. Bein "Colloidal zeolites as host matrix for copper nanoclusters," Chem. Mater. 18, 3373-3380 (2006).

47. J. Kelly, M. R. Gleeson, C. Close, F. T. O'Neill, and J. T. Sheridan, "Temporal response and first order volume changes during grating formation in photopolymers," J. Appl. Phys. 99, 113105 (2006).

48. M. R. Gleeson, J. Guo, and J. T. Sheridan, "Optimisation of photopolymers for holographic applications using the non-local photopolymerization driven diffusion model," Opt. Express 19, 2242322436 (2011)

49. M. V. Deshmukh, A. A. Vaidya, M. G. Kulkarni, P. R. Rajamohanan, and S. Ganapathy, "LCST in poly( $N$-isopropylacrylamide) copolymers: high resolution proton NMR investigations," Polymer 41, 7951-7960 (2000).

50. K. Jain, R. Vedarajan, M. Watanabe, M. Ishikiriyama, and N. Matsumi, "Tunable LCST behavior of poly( $N$-isopropylacrylamide/ionic liquid) copolymers," Polym. Chem. 6, 6819-6825 (2015).

51. M. Irfan, T. Mikulchyk, S. Martin, and I. Naydenova, "Investigation of the temperature response of photopolymer material used for holographic sensor," in Proceedings 15th International Bhurban Conference of Applied Sciences and Technology (IBCAST) (2018).

52. T. Mikulchyk, S. Martin, and I. Naydenova, "Humidity and temperature effect on properties of transmission gratings recorded in PVA/AAbased photopolymer layers," J. Opt. 15, 105301 (2013). 